\section{Barreiras, Adaptabilidade, Empregabilidade e Satisfação: Percepções de Carreira de Formandos em Administração}

\author{
Barriers, Adaptability, Employability, and Satisfaction: Career Perceptions of \\ Business Students
}

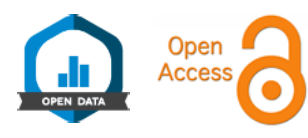

\author{
Mariana Ramos de Melo*1 1 \\ Priscilla de Oliveira Martins-Silva ${ }^{10}$ \\ Alexsandro Luiz de Andrade ${ }^{2}$ \\ Ralf Luis de Moura ${ }^{1}$
}

\section{RESUMO}

Objetivo: esta pesquisa pretende verificar a influência das percepções de barreiras de carreira e de adaptabilidade na empregabilidade e na satisfação com a carreira entre formandos em Administraçáo em instituiçôes de educação superior. Métodos: realizou-se uma pesquisa do tipo survey com 358 estudantes dos últimos semestres da graduação. A análise dos dados envolveu estatística descritiva, teste de hipótese da diferença entre médias amostrais e modelagem de equaçóes estruturais. Resultados: houve diferenças significativas nas percepçôes de barreiras de carreira conforme o sexo e a cor. No teste das hipóteses, constatou-se que barreiras contextuais de carreira não predizem a empregabilidade e a satisfação, ao contrário do que era esperado. Já a adaptabilidade se revelou como preditora de ambas, e a empregabilidade se revelou como preditora da satisfação. Conclusóes: os resultados reforçam que as características sociodemográficas dos indivíduos são indicadores potenciais para a compreensão das percepçóes de barreiras de carreira. Ademais, o desenvolvimento contínuo pelos estudantes da adaptabilidade (preocupação, controle, curiosidade, confiança) para construir as carreiras e a própria vida influencia de forma importante as percepçóes favoráveis de capacidades gerais para o trabalho (empregabilidade) e de sucesso na carreira.

Palavras-chave: desenvolvimento de carreira; barreiras de carreira; adaptabilidade; sucesso de carreira; educaçáo superior.

* Autor Correspondente.

1. Universidade Federal do Espirito Santo, Programa de Pós-Graduação em Administração, Vitória, ES, Brasil. 2. Universidade Federal do Espírito Santo, Programa de Pós-Graduação em Psicologia, Vitória, ES, Brasil.

Como citar: Melo, M. R. de, Martins-Silva, P. de O., Andrade, A. L. de, \& Moura, R. L. de. (2021). Barreiras adaptabilidade, empregabilidade e satisfação: Percepções de carreira de formandos em Administração. Revista de Administração Contemporânea, 25(6), e190124. https://doi.org/10.1590/1982-7849rac2021 190124.por

\section{ABSTRACT}

Objective: this study was aimed to verify how perceptions of career barriers and adaptability held by senior undergraduate students attending Business Administration programs influence employability and career satisfaction. Method: a survey was conducted among 358 senior undergraduate students. Data analysis included descriptive statistics, hypothesis tests for differences between means, and structural equation modeling. Results: significant differences were found in individuals' perceptions regarding career barriers depending on sex and race. Contrary to the expected, the hypothesis test showed that contextual career barriers do not predict employability or satisfaction. Adaptability, in turn, predicted both, while employability predicted satisfaction. Conclusions: the results reinforce that sociodemographic characteristics are potential indicators to support understanding of perceived career barriers. Additionally, the students' continued development of adaptability (concern, control, curiosity, confidence) to advance their careers and life plays an important role, positively influencing perceptions of overall abilities for work (employability) and career success.

Keywords: career development; career barriers; adaptability; career success; higher education.

Classificação JEL: O15, A2, J28.

Editor-chefe: Wesley Mendes-da-Silva (Fundação Getulio Vargas, EAESP, Brasill) eristas: Christine Schröeder (Universidade Federal do Rio Grande do Sul, EA, Brasil) (a) Ana Paula Moreno Pinho (Universidade Federal do Ceará, Brasil) ]

Relatório de Revisão por Pares: O Relatório de Revisão por Pares está disponivel neste link externo. Recebido: 25/03/2019 Última versão recebida em: 02/02/2021 Aceite em: 03/02/202

\begin{tabular}{|c|c|c|c|c|c|c|c|c|c|}
\hline & 1 & 2 & 3 & 4 & 5 & 6 & 7 & 8 & 9 \\
\hline $1^{\circ}$ rodada & (x) & $\stackrel{9}{2}$ & (x) & (x) & (x) & $\stackrel{9}{2}$ & & & \\
\hline $2^{a}$ rodada & ڤి & & & & & & & & \\
\hline $3^{a}$ rodada & $\stackrel{\varphi}{2}$ & & & & & & & & \\
\hline
\end{tabular}




\section{INTRODUÇÃO}

Questóes inerentes à carreira inserem-se no conjunto de interesses e preocupaçóes que envolvem os indivíduos ao longo de suas vidas, sendo a temática relevante na literatura acadêmica principalmente por assumir significados cada vez mais contextualizados. Além disso, o tema exerce impacto não só para os profissionais dos inúmeros segmentos de atuação, mas também para as organizaçóes, tendo em vista a influência da carreira em importantes aspectos da vida de seus membros, como o desempenho, a saúde e o bem-estar (Magalháes \& Bendassolli, 2013). Na era pós-moderna atual, as teorias de carreira enfatizam a perspectiva da gestáo de carreira associada à gestáo da vida (Di Fabio, 2019) e, em termos práticos, o principal objetivo na orientaçáo profissional e de carreira vem sendo garantir que o indivíduo tenha a satisfaçáo na carreira maximizada ao longo da vida (Perera \& Athanasou, 2019).

O tema sobre desenvolvimento de carreira relacionase, nesse sentido, com as diversas transformaçóes que vêm afetando o mundo corporativo. As ressignificações do vínculo entre indivíduo e trabalho vêm sendo abordadas de maneiras diversas na academia. Dentre as inúmeras transformaçóes, pode-se mencionar a crescente preocupação com a empregabilidade (Perera \& Athanasou, 2019) e reflexividade sobre a carreira (Perera \& Athanasou, 2019; Savickas, 2016), a instabilidade das relaçóes empregatícias (Di Fabio, 2019), o aumento do trabalho informal e a acelerada transformação digital e automação de processos (Perera \& Athanasou, 2019).

Em um contexto de trabalho altamente fluido e flexível, os indivíduos tendem a experimentar maior instabilidade $\mathrm{e}$ insegurança (Di Fabio, 2019). Ao considerar o mercado de trabalho brasileiro, os últimos períodos de crise econômica e financeira instaurados no país (Barbosa Filho, 2017; Instituto Brasileiro de Geografia e Estatística [IBGE], 2020; Oreiro, 2017) podem influenciar significativamente as percepçóes pessoais em relação à gestão da carreira. As crenças individuais tornam-se cada vez mais relevantes no contexto da carreira, e comportamentos e características de autogerenciamento da própria carreira são cada vez mais demandados aos indivíduos no cenário atual do século XXI (Di Fabio, 2019; Lent \& Brown, 2013).

As percepções de barreiras de carreira (Swanson, Daniels, \& Tokar, 1996) inserem-se nesse cenário atual de transformaçôes e turbulências. No contexto de carreira e trabalho, as mudanças provocadas pela transiçáo de uma sociedade industrial embasada em sistemas fabris para uma sociedade baseada no conhecimento requerem novas habilidades e recursos dos profissionais - dentre eles, destaca-se a adaptabilidade (Savickas, 2013). Assim, observa-se hoje a desejável (ou até obrigatória) capacidade de ajuste e de adaptação contínua dos indivíduos em meio ao desenvolvimento econômico, social e tecnológico ininterrupto (Johnston, 2016).

Conforme Dahling, Melloy e Thompson (2013), a maior parte dos estudos que envolveram barreiras de carreiras manteve a ênfase em barreiras percebidas no nível da própria pessoa, ou seja, barreiras percebidas em si mesmo. Considerando isso, esta pesquisa, diferentemente, teve o enfoque no estudo de barreiras percebidas no contexto. Em relaçáo ao construto da adaptabilidade, outra lacuna na literatura foi considerada nesta investigação a partir do que afirma Johnston (2016). De acordo com a autora, configura-se uma oportunidade aos pesquisadores a investigaçáo sobre a adaptabilidade de carreira em um público-alvo que esteja vivenciando momentos de transiçóes - ou, conforme a teoria, momentos de miniciclos (Savickas, 2013). Esses momentos são marcados por certa desestabilização da carreira e, por isso, os indivíduos são chamados a utilizarem em maior nível as habilidades de planejamento, exploraçáo, gerenciamento, dentre outras (Johnston, 2016; Savickas, 2013). Tais características são próprias da adaptabilidade de carreira.

Considerando o exposto, a questão motivadora deste estudo englobaa percepçáo individual de discentes universitários finalistas no curso de graduação em Administração. A partir de tais lacunas, um modelo teórico é sugerido embasado nos construtos Barreiras de Carreira (contextuais) e Adaptabilidade de Carreira, a fim de averiguar o impacto destes em percepçóes de resultados na carreira - Empregabilidade e Satisfação. As hipóteses são definidas baseando-se em argumentos teóricos e empíricos. Salienta-se ainda que o estudo de percepçóes de resultados alcançados na carreira é relevante não apenas para as organizaçóes, mas também aos indivíduos, principalmente no que tange ao processo de desenvolvimento e autogestáo de suas próprias carreiras.

Define-se, pois, o seguinte objetivo de pesquisa: verificar a influência das percepçóes de barreiras de carreira e de adaptabilidade na empregabilidade e na satisfação com a carreira entre formandos em Administração em instituiçôes de educação superior (IES). Como plano metodológico, esta investigação caracteriza-se como uma pesquisa de levantamento (survey) (Cozby, 2003), com amostra de característica não probabilística. Para a análise dos dados, foram utilizadas técnicas estatísticas descritivas e análises multivariadas (Hair, Black, Babin, Anderson, \& Tatham, 2009) por meio de associaçóes dos construtos.

Explica-se, por fim, que a relevância e a originalidade deste estudo estáo respaldadas nas seguintes particularidades: (a) contribuiçáo para o desenvolvimento dos estudos sobre carreira no Brasil, os quais ainda são incipientes; (b) investigação da carreira pela perspectiva individual a partir da vinculação da teoria de barreiras de carreiras (Swanson et al., 1996) - ancorada na perspectiva social cognitiva de carreira de Lent, Brown e Hackett (1994) - e de adaptabilidade de 
carreira, incluída na teoria de construção da carreira de Savickas (2013); (c) estudo em conjunto das percepçóes de barreiras e adaptabilidade de carreira, empregabilidade e satisfação, o que irá fornecer explicaçôes sobre o fenômeno e ampliar pesquisas existentes na academia sobre tais conceitos teóricos; e (d) ampliação das explicaçóes sobre o fenômeno em um contexto de turbulência, inquietaçóes e angústias quanto aos aspectos sociais e econômicos no mercado de trabalho.

Por fim, em termos práticos, esperam-se alcançar contribuições com a evidenciação das percepçóes de estudantes ao fim de um curso de graduação. Almeja-se contribuir para o direcionamento de estratégias renovadoras e específicas que influenciem positivamente aspectos cognitivos dos indivíduos durante a sua trajetória na formação educacional. Além disso, aspectos de diversidade foram retratados no contexto da carreira, o que poderá contribuir para a reflexão crítica acerca da heterogeneidade estrutural do mercado de trabalho brasileiro, das açōes de IESs em torno dos estudantes e, de forma geral, do pensamento atual e coletivo sobre questóes inerentes à carreira.

\section{REFERENCIAL TEÓRICO}

\section{Carreira}

O mundo do trabalho e as organizaçóes passaram ao longo dos anos por inúmeras mudanças em suas operaçóes e, devido a isso, evidencia-se hoje a importância da atuação do indivíduo para o desenvolvimento da carreira. A característica de imprevisibilidade das carreiras exige atualmente que os profissionais adotem normas não tradicionais de sucesso na carreira e se preocupem com experiências que possam estimular o aprendizado e a adaptabilidade (Vianen, Pater, \& Preenen, 2019). Houve, nesse sentido, modificação das possibilidades identificadas pelas pessoas para a construção de suas carreiras.

Dessa forma, a concepção da carreira organizacional técnico-científica (associada à ascensão na escala hierárquica e às promoçóes) não se torna mais adequada, uma vez que nem sempre valoriza qualidades como iniciativa, criatividade e reflexividade (Pinho, Kilimnik, \& Andrade, 2015). A definiçâo mais recente e integrativa de carreira - coerente com as transformaçôes nas quais as relações de trabalho estiveram inseridas - envolve expectativas, comportamentos, cogniçóes e sentimentos dos indivíduos, os quais participam de um processo que abarca o autodesenvolvimento orientado por propósitos de vida e de trabalho (Magalháes \& Bendassolli, 2013). Dessa forma, a carreira pode ser definida como um construto multidimensional influenciado por fatores diversos (social, econômico, psicológico) e pelas circunstâncias vivenciadas ao longo da vida (Magalhães \& Bendassolli, 2013).

\section{Contexto atual do mercado de trabalho}

Ao considerar o contexto atual do mercado de trabalho e do desenvolvimento de carreira no Brasil, torna-se relevante refletir sobre como alguns grupos estão se inserindo nesse cenário de inúmeras particularidades. Pesquisas recentes reforçam que a crise econômica vigente no país reflete na perda da capacidade financeira do governo, o que influencia o aumento do trabalho informal e a redução da oferta de empregos (Barbosa Filho, 2017; Oreiro, 2017; Santos \& Gimenez, 2015). Além da crise econômica nacional, diversas transformaçôes vêm afetando o mundo do trabalho - o que ocorre também em nível mundial, como o aumento dos trabalhos temporários e informais, do teletrabalho e do desemprego (Perera \& Athanasou, 2019). Nessa conjuntura altamente fluida, imprevisível e de transiçóes, os indivíduos precisam lidar com instabilidade e insegurança frente ao trabalho, sendo que a própria carreira é caracterizada como um lugar de mudanças (Di Fabio, 2019).

Especificamente sobre o cenário nacional, observa-se que a taxa de desocupaçáo foi de $14,6 \%$ no terceiro trimestre de 2020 - equivalente a mais de 14 milhôes de pessoas desocupadas (IBGE, 2020). Ao considerar a populaçáo jovem, os números são ainda mais elevados. Para as pessoas com idades entre 18 e 24 anos, a taxa de desocupação foi de $31,4 \%$ no mesmo período - muito superior ao valor da média nacional (IBGE, 2020). Santos e Gimenez (2015) explicam que, historicamente, os jovens constituem um segmento da força trabalhista com elevada vulnerabilidade social. As características do mercado de trabalho nacional, bem como do processo de inclusão de jovens nesse mercado, são produtos da forma como ocorreu o desenvolvimento econômico no país - que apresenta altos índices de desigualdade regional, econômica e social. Além disso, a taxa de participaçáo laboral dos jovens no Brasil esteve associada a exploraçóes de trabalho com influências negativas sobre a formação educacional desse grupo (Santos \& Gimenez, 2015).

No tocante às características de cor ou raça da força de trabalho brasileira, pesquisas recentes indicaram que as pessoas de cor branca, embora não constituíssem o maior grupo na populaçáo total do Brasil e na força de trabalho, compreenderam o maior percentual da populaçáo ocupada com $46,2 \%$, seguidos dos pardos com $43,9 \%$ e dos negros com 8,9\% (Instituto Brasileiro de Geografia e Estatística [IBGE], 2017). Já em relação à taxa de desocupação, verificou-se ser maior entre negros $(19,1 \%)$ e pardos $(16,5 \%)$ em 2020 ambos acima da média nacional -, enquanto a taxa das pessoas que se declararam de cor branca foi de $11,8 \%$ (IBGE, 2020).

Ao considerar o sexo, identificou-se que, das pessoas brasileiras aptas ao trabalho, as mulheres formaram o maior grupo no terceiro trimestre de 2020 (53,2\%). A situação é contrária, porém, quando se compara o nível da ocupação. Esse índice apontou diferença significativa entre os sexos, sendo o 
dos homens $(57,3 \%)$ aproximadamente dez pontos percentuais acima da média nacional $(47,1 \%)$, e o das mulheres, dez pontos abaixo $(38,1 \%)$. Por fim, considerando a taxa de desocupação em 2020, há também diferenças. A taxa das mulheres $(16,8 \%)$ está acima da média nacional de 14,6\%, enquanto a taxa dos homens (12,8\%) está abaixo da média (IBGE, 2020).

Os dados expostos são relevantes para evidenciar as dificuldades no mercado de trabalho que são enfrentadas por grupos de pessoas, tendo em vista suas características sociodemográficas. Em concordância com o que afirmam Santos e Gimenez (2015), o processo de desenvolvimento socioeconômico no Brasil apresenta características demasiadamente concentradoras e excludentes, o que reflete ainda hoje nas estatísticas que envolvem o mercado de trabalho nacional. Percebe-se, com isso, que as diferenças individuais e as questóes de diversidade exercem impacto sobre as relaçóes trabalhistas. Nesse sentido, considerando que o mercado de trabalho no Brasil é estruturalmente heterogêneo (Santos \& Gimenez, 2015), estudos que impulsionam reflexões críticas acerca dessa característica merecem destaque devido à relevância e urgência do tema.

\section{Construtos da pesquisa e desenvolvimento das hipóteses}

O construto Barreiras de Carreira pode ser definido como todas as condiçóes que dificultam o progresso do indivíduo na carreira, sejam internas, sejam externas. As barreiras internas são aquelas percebidas em si mesmo pelo indivíduo, como a indecisão ou a insegurança. Já as barreiras externas são aquelas percebidas no ambiente, como, por exemplo, no país, na cidade em que se vive ou no próprio mercado de trabalho (Lent, Brown, \& Hackett, 2000; Swanson et al., 1996). O conceito originou-se a partir da década de 1970 , no contexto em que se buscava investigar as particularidades do desenvolvimento da carreira das mulheres (Cardoso, 2009).

Especificamente, esta pesquisa tem a ênfase no estudo de barreiras percebidas externamente pelos indivíduos. Tais barreiras podem se relacionar com aspectos contextuais referentes a variados aspectos, como a situação econômica local, o acesso a informaçóes, os contratos trabalhistas precários, as restriçóes de oportunidades e a discriminação (Melo, MartinsSilva, \& Andrade, 2020). Pesquisas desenvolvidas recentemente apontaram barreiras diversas percebidas no contexto, incluindo restriçóes contextuais financeiras e falta de oportunidades de trabalho entre universitários (Urbanaviciute, Pociute, Kairys, \& Liniauskaite, 2016).

Estudos empíricos já evidenciaram também que há diferenças nas crenças associadas à carreira entre homens e mulheres (Faria, Taveira, \& Saavedra, 2008; Lipshits-Braziler \& Tatar, 2012). Cardoso (2009) investigou jovens e constatou que as mulheres apresentavam médias de percepçáo de barreiras de carreira superiores às dos homens. Mais recentemente, Silva (2016) conduziu testes de invariância com grupos diferentes e constatou que os homens apresentaram índices mais elevados de aspectos psicológicos positivos de carreira, enquanto as mulheres se mostraram mais influenciadas por pensamentos pessimistas.

Outros aspectos de diversidade englobados em estudos prévios também já demonstraram diferenças de percepçóes de barreiras externas de carreira em indivíduos. Kim e O’Brien (2018) desenvolveram um estudo sobre barreiras e envolveram grupos diferentes de mulheres universitárias. Em comparação com as mulheres brancas, todos os grupos de mulheres negras relataram maiores barreiras profissionais devido ao racismo, e maiores barreiras educacionais devido à discriminaçáo racial. Considera-se, a partir dos estudos, que as percepçóes de empecilhos na carreira diferem conforme características individuais - como o sexo e a cor (Lipshits-Braziler \& Tatar, 2012).

Para esta investigação, o enfoque em barreiras externas seguirá os achados da pesquisa de Melo, Martins-Silva e Andrade (2020) por meio de dimensóes específicas, sendo elas: Falta de Suporte (dificuldades percebidas no ambiente em que se vive, como limitaçáo de serviços de orientação e acesso restrito às informações); Discriminação Étnica (discriminação em relação à cor/etnia); Discriminaçẫo Sexual (discriminação em relação ao sexo biológico/gênero); e Restrição de Oportunidades (dificuldades percebidas quanto a oportunidades no contexto geral do mercado de trabalho e na profissão). Assim, propóe-se a primeira hipótese:

H1 - Existem diferenças no grau de influência das percepções de Barreiras de Carreira em relação à falta de suporte, discriminação e restrição de oportunidades de acordo com variáveis sociodemográficas, em que:

$\mathrm{H} 1 \mathrm{a}$ - as pessoas do sexo feminino apresentam maiores médias que as pessoas do sexo masculino; e

$\mathrm{H} 1 \mathrm{~b}$ - as pessoas de cor parda ou negra apresentam maiores médias que as pessoas de cor branca.

Percepçóes sobre resultados alcançados na carreira são também englobados nesta pesquisa, como é o caso da Empregabilidade. Os estudos que envolvem a empregabilidade ganharam força a partir do final dos anos 1990, tendo sido inicialmente estudada tanto em nível individual como em nível organizacional, e também em disciplinas diversas, como Administração e Psicologia (Heijde \& Van Der Heijden, 2006). Recentemente, a empregabilidade vem sendo abordada na literatura como uma substituiçáo da estabilidade no emprego - já que esta vem sendo modificada pela natureza atual dos contratos de trabalho (Ladeira, Oliveira, Melo-Silva, \& Taveira, 2019). 
Considerando pesquisas recentes, é possível definir empregabilidade como um fenômeno que envolve conjuntamente aspectos psicológicos e sociais que abrangem a aquisição, criação ou realização contínua de habilidades para o trabalho (entrada e manutenção) por meio do uso de ótimas competências (De Vos, De Hauw, \& Van der Heijden, 2011; Heijde \& Van Der Heijden, 2006). Logo, assume-se que a empregabilidade percebida favorece as percepçóes quanto ao valor que os indivíduos possuem frente ao mercado de trabalho e quanto ao nível de satisfação com a carreira. Em suma, a empregabilidade vem sendo relacionada com as percepçóes individuais quanto aos resultados alcançados na carreira (Silva, 2016) e tem se tornado um conceito cada vez mais relevante nas relações profissionais contemporâneas (Praskova, Creed, \& Hood, 2015).

Sequencialmente, a Satisfação com a Carreira é também incluída no fenômeno estudado neste trabalho, tratando-se de uma percepção de resultado. Esta define-se como os julgamentos individuais do que é considerado sucesso na carreira, o qual pode ser mensurado com base em aspectos objetivos e subjetivos. Os primeiros referem-se a questôes externas ao indivíduo, como cargo hierárquico, promoções e salário. Os aspectos subjetivos, por sua vez, baseiam-se na perspectiva psicológica do indivíduo em relação à sua carreira, envolvendo reconhecimento, sentido, propósito e expectativas futuras (Kuijpers, Schyns, \& Scheerens, 2006). Assume-se, pois, que o nível de satisfação com a carreira caracteriza-se como uma avaliaçẫo individual única, e está associado a elementos que influenciam comportamentos e percepçóes diversas do ser humano.

Tanto a empregabilidade quanto a satisfação podem ser consideradas percepçóes sobre resultados alcançados na carreira. Com isso, a partir do entendimento inicial sobre barreiras, assume-se que tais percepçôes influenciam a empregabilidade e a satisfação. Silva e Andrade (2016) comprovaram, por meio de um estudo sobre pensamentos negativos de carreira, que esses tipos de julgamentos demonstram relação negativa com as percepçóes de resultados com a carreira. Mostram-se, destarte, como fatores que dificultam o desenvolvimento da vida profissional dos indivíduos. Especificamente sobre o nível de satisfaçáa, London (2014) explica que a percepçáo de barreiras de carreira influencia de maneira negativa o nível de satisfaçáo com a carreira. Ainda, Bullock-Yowell, Peterson, Reardon, Leierer e Reed (2011) já demonstraram que os pensamentos negativos de carreira são empecilhos às percepções de satisfação, tanto com a carreira quanto com a vida. Logo, propóem-se as hipóteses:

H2 - Há uma predição significativa negativa das percepções de Barreiras de Carreira sobre a Empregabilidade percebida; e

H3 - Há uma predição significativa negativa das percepçóes de Barreiras de Carreiras sobre o nível de
Satisfação que o indivíduo detém a respeito de sua carreira.

Por fim, a Adaptabilidade também foi envolvida nesta investigação. $\mathrm{O}$ termo significa a capacidade individual de mudar e de se adaptar às novas circunstâncias sem dificuldade elevada. A necessidade de adaptação às mudanças constantes às quais os indivíduos estão expostos deve ser contínua para o desenvolvimento de suas carreiras, em detrimento de ações lineares e previsíveis. Nessa perspectiva, a adaptabilidade de carreira é definida, em sentido amplo, como a habilidade para lidar náo apenas com tarefas previsíveis de planejamento de carreira, mas também com ajustes imprevisíveis impostos pela vida pessoal e profissional (Savickas, 1997).

A Adaptabilidade de Carreira é considerada multidimensional e inclui quatro competências comportamentais: Preocupação (PR), Controle (CR), Curiosidade (CS) e Confiança (CO). A PR engloba o planejamento da carreira e o senso de orientaçáo quanto ao futuro profissional. $\mathrm{O} C R$ envolve a responsabilidade para o desenvolvimento da carreira por meio de postura ativa, enfrentamento de questóes adversas e manutençẫo do domínio sobre a carreira. Por sua vez, a CS refere-se a comportamento exploratório de possibilidades e cenários, além de açóes de iniciativa e busca por experiências diversas. Já a CO contempla atitudes positivas em relaçáo à própria competência, refletindo em esforços para o alcance de objetivos e superação de obstáculos (Savickas, 1997, 2013; Savickas \& Porfeli, 2012).

O estudo de Silva (2016) constatou que aspectos benéficos como a adaptabilidade podem influenciar de forma significativa as percepçóes de resultados alcançados na carreira. $\mathrm{O}$ autor explica que características psicológicas positivas (como preocupação, controle, dentre outras) auxiliam o indivíduo a manter uma orientaçáo otimista de carreira, o que favorece o desenvolvimento de novas habilidades para manter-se empregado. Gamboa, Paixão e Palma (2014), considerando o contexto de transiçáo entre estudos e trabalho, verificaram associaçóes positivas entre adaptabilidade de carreira e empregabilidade percebida junto a estudantes do ensino superior. Em outra pesquisa, Ladeira, Oliveira, Melo-Silva e Taveira (2019) também identificaram efeito significativo e positivo entre adaptabilidade de carreira e empregabilidade percebida com o público de universitários cursando o último ano da graduação.

Em relaçáo a estudos que envolveram adaptabilidade e satisfação, Ambiel, Hernández e Martins (2016) constataram que a satisfação com o curso de graduação pode ser considerada um reflexo do processo de adaptaçáo pelo aluno. Nessa perspectiva, considera-se que um dos resultados do processo de construção da carreira é a própria satisfação obtida (Savickas \& Porfeli, 2012). Propóem-se, pois, a quarta e quinta hipóteses desta pesquisa: 
H4-Há uma predição significativa positiva do construto Adaptabilidade sobre a Empregabilidade percebida; e

H5 - Há uma predição significativa positiva do construto Adaptabilidade sobre o nível de Satisfação que $\mathrm{o}$ indivíduo detém a respeito de sua carreira.

No entendimento de Lo Presti e Pluviano (2016), a empregabilidade pode ser considerada um recurso pessoal que os indivíduos desenvolvem no decorrer de suas vidas profissionais por meio de competências e aptidóes valiosas, e objetivando aumentar o sucesso na carreira. Mais recentemente, Vianen, Pater e Preenen (2019) sustentaram que a maior imprevisibilidade nas relaçóes profissionais e as constantes mudanças no mercado de trabalho exigem que os indivíduos avaliem suas próprias carreiras em termos de empregabilidade. Os autores justificam que as percepçóes de empregabilidade podem ser promovidas - por exemplo, em ambientes de trabalho e por meio de experiências desafiadoras -, e que estas se relacionam diretamente com as percepçóes individuais de sucesso na carreira. A partir disso, propóe-se a última hipótese desta pesquisa:

H6 - Há uma predição significativa positiva das percepçóes de Empregabilidade sobre o nível de Satisfação com a carreira.

Os argumentos apresentados, juntamente com as hipóteses, originaram o modelo estrutural hipotético apresentado na Figura 1, o qual será averiguado neste trabalho.

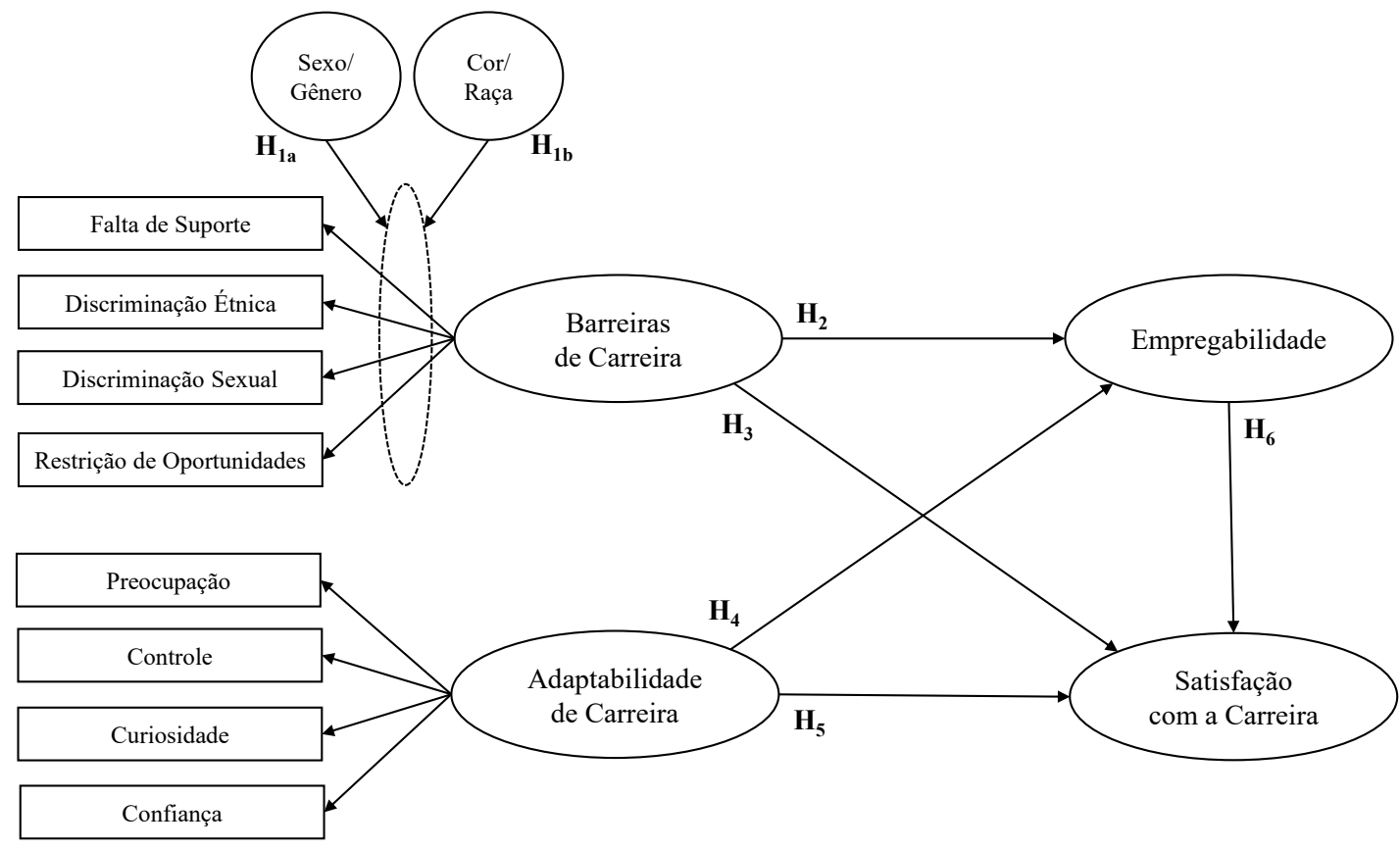

Figura 1. Modelo estrutural hipotético.

Fonte: Elaborado pelos autores. Modelo estrutural embasado em estudos prévios e proposto pela presente pesquisa.

\section{MÉTODO}

\section{Participantes}

Foram obtidas na totalidade 358 respostas válidas. $\mathrm{O}$ poder do teste foi calculado por meio do G*Power considerando a análise post hoc e o resultado foi significativo e satisfatório, obtendo valor próximo a $100 \%$. A maior parte dos participantes era do sexo feminino $(\mathrm{N}=207 ; 57,8 \%)$, com média de idade de 27 anos ( $\mathrm{DP}=6,03)$. Destaca-se que
$78,3 \%(\mathrm{~N}=280)$ apresentaram idades entre 19 e 30 anos. Houve prevalência de pessoas solteiras ( $\mathrm{N}=248 ; 69,3 \%)$, de cor branca $(\mathrm{N}=155 ; 43,3 \%)$ e parda $(\mathrm{N}=150 ; 41,9 \%)-$ apenas 49 pessoas $(13,7 \%)$ se declararam de cor negra. Grande parte dos participantes exercia atividade remunerada $(\mathrm{N}=305$; $85,2 \%)$. A renda familiar média mensal se concentrou entre $\mathrm{R} \$$ $1.405,51$ e R \$ 4.216,50 (44,4\%). Por fim, em relação às IESs participantes, 254 (70,9\%) foram de natureza social privada, com a prevalência do curso noturno $(\mathrm{N}=315,88,0 \%)$. 


\section{Caracterização da pesquisa e aspectos éticos}

Este estudo caracteriza-se como uma pesquisa correlacional por meio do método de levantamento (survey) (Cozby, 2003). Ressalta-se que os procedimentos adotados foram embasados nos critérios da ética em pesquisa com seres humanos, de acordo com a resoluçáo n. ${ }^{\circ} 466 / 12$ do Conselho Nacional de Saúde. O Comitê de Ética em Pesquisa com Seres Humanos (CEPSH) aprovou o estudo sob o parecer de número 2.264.099.

\section{Instrumentos de coleta de dados}

Os instrumentos utilizados nesta pesquisa foram estes, conforme a ordem de aplicação: Inventário de Percepção de Barreiras de Carreira (IPBC) (coeficientes ômega de McDonald $[\omega]=0,81$ a 0,86): desenvolvido por Cardoso (2009) e adaptado e reduzido por Melo et al. (2020), avalia percepçóes sobre barreiras de carreira externas ao indivíduo. É composto por 16 itens organizados em escala do tipo Likert de sete pontos, sendo estas as dimensóes, com quatro itens em cada: Discriminação Étnica (DE) (ex.: Ser alvo de discriminação racial em promoçóes na carreira); Discriminaçáo Sexual (DS) (ex.: Ser alvo de assédio sexual no trabalho); Falta de Suporte (FS) (ex.: Ter contratos de trabalho precários, como trabalhar sem contrato, com contratos temporários sem carreira definida, etc.); e Restrição de Oportunidades (RO) (ex.: Não ter oportunidades de progressão na profissão).

Escala de Adaptabilidade de Carreira (EAC) (coeficientes alfas de Cronbach $[\alpha]=0,83$ a 0,89): desenvolvida por Savickas e Porfeli (2012) e adaptada por Audibert e Teixeira (2015), avalia percepçóes sobre habilidades desenvolvidas para construir as carreiras e as próprias vidas. É composta por 24 itens organizados em escala do tipo Likert de cinco pontos, sendo estas as dimensóes, com seis itens em cada uma: Preocupação (ex.: Pensar sobre como será o meu futuro); Controle (ex.: Manter-me entusiasmado[a] e otimista); Curiosidade (ex.: Explorar o ambiente ao meu redor); e Confiança (ex.: Realizar as tarefas de forma eficiente).

Escala Geral de Empregabilidade Percebida (EEP) $(\alpha=0,79)$ : desenvolvida por Silva (2016), avalia percepçóes gerais sobre o desenvolvimento de habilidades para o trabalho e o alcance de metas de carreira. É composta por oito itens organizados em escala do tipo Likert de cinco pontos. Ex.: Acha que no futuro você irá conseguir um emprego que lhe satisfaça?

Escala Geral de Satisfação com a Carreira (ESC) $(\alpha=$ 0,80): desenvolvida por Greenhaus, Parasuraman e Wormley (1990) e adaptada por Silva (2016), avalia níveis globais de satisfação com a carreira. É composta por cinco itens organizados em escala do tipo Likert de cinco pontos. Ex.: Estou satisfeito com o sucesso que tenho alcançado em minha carreira.
Questionário Sociodemográfico: desenvolvido neste estudo e composto por perguntas sobre características sociais e demográficas dos participantes. Ex.: Qual a sua idade? Você desenvolve alguma atividade remunerada?

\section{Procedimentos de coleta e análise de dados}

A coleta de dados foi conduzida em IESs de natureza pública e privada, localizadas nos estados do Espírito Santo e de Minas Gerais, em que o critério de escolha foi pela conveniência (Cozby, 2003). Diversas IESs foram contatadas, e sete demonstraram abertura para a pesquisa e permitiram a coleta de forma presencial. $\mathrm{O}$ acesso aos discentes foi conduzido em sala de aula, de forma coletiva e voluntária.

Os dados primários foram processados e analisados por meio da utilização destes pacotes estatísticos: G*Power, versão 3.1.9.2; Statistical Package for Social Sciences (SPSS), versão 21; JAMOVI, versão 0.8.1.5; e Analysis of Moment Structures (AMOS Graphics), extensão do SPSS. Inicialmente, o G*Power foi utilizado para verificar o poder do teste alcançado. Pelo SPSS, foram conduzidas análises estatísticas descritivas para a caracterização dos discentes. Ademais, o software foi utilizado para realizar testes de avaliação da significância estatística da diferença entre médias amostrais (H1) (Hair et al., 2009).

Para averiguar a consistência interna, o JAMOVI foi utilizado para calcular o coeficiente ômega de McDonald ( $\omega)$ (Trizano-Hermosilla \& Alvarado, 2016), o qual é considerado uma medida robusta para averiguar a precisáo de instrumentos de pesquisa (Dunn, Baguley, \& Brunsden, 2014). Sequencialmente, para verificar as hipóteses de dependência entre os construtos ( $\mathrm{H} 2 \mathrm{a} \mathrm{H} 6)$, foram realizadas análises multivariadas por meio da modelagem de equaçóes estruturais (SEM) (Hair et al., 2009) pelo AMOS Graphics.

Com o objetivo de verificar a adequação do modelo estrutural, estes indicadores foram considerados: (1) $\chi^{2}$ normado (proporçáo simples de $\chi 2$ com o grau de liberdade: $\chi 2 / \mathrm{gl})$ : valor ótimo menor ou igual a $3 / 10$, e aceitável até $5 / 0$; (2) comparative fit index (CFI): maior que 0,90 ; (3) índice de Tucker-Lewis (TLI): maior que 0,90; e (4) root mean square error of approximation (RMSEA): ótimo entre 0,05 e 0,08 para intervalo de $90 \%$ de confiança, aceitável até 0,10 (Hair et al., 2009). Ressalta-se que todos os instrumentos foram testados e verificados psicometricamente em termos de propriedades de evidências de validade e precisão para amostra em análise e natureza teórica dos construtos investigados. Informaçóes adicionais estão disponíveis na dissertaçáo de Melo (2018) e artigo de Melo et al. (2020), não estando integralmente disponíveis neste manuscrito por questóes de pertinência e espaço disponível. 


\section{RESULTADOS}

\section{Descrição estatística}

Foram verificadas estatísticas descritivas para cada instrumento utilizado. Inicialmente, o IPBC apresentou bons índices de confiabilidade de suas quatro dimensóes, sendo o coeficiente ômega de McDonald da escala total $(\omega=0,93)$ considerado excelente. Em relaçáo às médias, a maior foi na dimensão $\mathrm{RO}(4,35 ; \mathrm{DP}=1,43)$, enquanto a menor foi em $\mathrm{DE}$ $(3,54 ; \mathrm{DP}=1,80)-$ demais dimensōes: $\mathrm{FS}(4,07 ; \mathrm{DP}=1,54)$ e DS $(3,85 ; \mathrm{DP}=1,72)$. A média geral do inventário foi de $3,95(\mathrm{DP}=1,41)$. As correlaçóes entre as dimensóes do IPBC indicaram associaçôes significativas, positivas e com valores moderados a elevados. Os valores de $r$ variaram entre 0,61 a $0,81(p<0,01)$, sendo a correlação com valor mais elevado entre DS e DE $(r=0,81 ; p<0,01)$; e as correlaçóes com valores mais baixos entre FS e DE, e RO e DE (ambos com $r=0,61$; $p<0,01)$.

Sequencialmente, os índices de confiabilidade das dimensóes da EAC variaram da seguinte forma: PR $(\omega=$ $0,83)$; CR $(\omega=0,75)$; CS $(\omega=0,84)$; e CO $(\omega=0,84)$. Esses valores evidenciam uma boa precisão dos fatores. A escala total obteve índice de 0,91 , sendo considerado excelente. Em relação às médias, o maior valor na $\mathrm{EAC}$ foi verificado na dimensão $\mathrm{CO}(4,25 ; \mathrm{DP}=0,59)$, enquanto a menor foi em CS $(3,85$;
$\mathrm{DP}=0,72)$. As demais dimensóes, $\mathrm{PR}(4,04 ; \mathrm{DP}=0,64)$ e $\mathrm{CR}$ $(4,05 ; \mathrm{DP}=0,59)$, apresentaram valores médios similares. $\mathrm{A}$ média geral da escala foi de 4,05 (DP = 0,51). As correlaçóes entre as dimensōes indicaram associaçóes positivas e significativas, em que os valores de $r$ variaram entre 0,35 a $0,63(p<0,01)$. A correlaçáo com valor mais elevado encontra-se entre $\mathrm{CO}$ e CS $(r=0,63 ; p<0,01)$, enquanto a mais baixa encontra-se entre CR e PR $(r=0,35 ; p<0,01)$.

A EEP e a ESC, por fim, apresentaram bons índices de confiabilidade, quais sejam, respectivamente $\omega=0,80$ e $\omega=0,88$. No tocante às médias, a $\operatorname{EEP}(3,94 ; \mathrm{DP}=0,56)$ obteve valor superior se comparada à ESC $(3,16$; DP $=0,84)$. Já a correlação entre as escalas indicou associação positiva significativa, com valor de $r$ igual a $0,45(p<0,01)$.

\section{Avaliação de diferenças entre grupos $(\mathrm{H} 1)$}

Para averiguar a significância estatística de diferenças de percepçóes de barreiras de carreira entre grupos com características sociodemográficas distintas, procedeu-se com o teste de hipótese da diferença de médias. As variáveis independentes consideradas foram o sexo (H1a) e a cor (H1b), conforme Tabela 1. O tamanho amostral mínimo foi respeitado de acordo com o software G*Power, qual seja, ao menos 118 participantes em cada grupo.

Tabela 1. Teste de diferenças de grupos: sexo e cor.

\begin{tabular}{|c|c|c|c|c|c|c|c|}
\hline Instrumento | Dimensôes & Sexo $\mid$ Cor & Média & $\begin{array}{l}\text { Desvio- } \\
\text { Padrão }\end{array}$ & Erro & Teste Levene & $T$ & $\begin{array}{c}p \\
\text { Teste de } \\
\text { Médias }\end{array}$ \\
\hline Barreiras de Carreira & $\begin{array}{c}\text { Masculino } \\
\text { Feminino }\end{array}$ & $\begin{array}{l}3,68 \\
4,13\end{array}$ & $\begin{array}{l}1,49 \\
1,32\end{array}$ & $\begin{array}{l}0,12 \\
0,09\end{array}$ & 0,02 & $-2,93$ & $\mathbf{0 , 0 0 * *}$ \\
\hline Discriminação Étnica (DE) & $\begin{array}{c}\text { Masculino } \\
\text { Feminino }\end{array}$ & $\begin{array}{l}3,34 \\
3,67\end{array}$ & $\begin{array}{l}1,86 \\
1,75\end{array}$ & $\begin{array}{l}0,15 \\
0,12\end{array}$ & 0,19 & $-1,73$ & 0,08 \\
\hline Discriminação Sexual (DS) & $\begin{array}{c}\text { Masculino } \\
\text { Feminino }\end{array}$ & $\begin{array}{l}3,33 \\
4,20\end{array}$ & $\begin{array}{l}1,77 \\
1,59\end{array}$ & $\begin{array}{l}0,15 \\
0,11\end{array}$ & 0,02 & $-4,77$ & $0,00^{* *}$ \\
\hline Falta de Suporte (FS) & $\begin{array}{c}\text { Masculino } \\
\text { Feminino }\end{array}$ & $\begin{array}{l}3,77 \\
4,27\end{array}$ & $\begin{array}{l}1,63 \\
1,44\end{array}$ & $\begin{array}{l}0,13 \\
0,10\end{array}$ & 0,01 & $-2,99$ & $0,00^{* *}$ \\
\hline Restrição de Oportunidades (RO) & $\begin{array}{c}\text { Masculino } \\
\text { Feminino }\end{array}$ & $\begin{array}{l}4,30 \\
4,38\end{array}$ & $\begin{array}{l}1,46 \\
1,41\end{array}$ & $\begin{array}{l}0,12 \\
0,10\end{array}$ & 0,48 & $-0,54$ & 0,59 \\
\hline Barreiras de Carreira & $\begin{array}{c}\text { Branca } \\
\text { Parda/Negra }\end{array}$ & $\begin{array}{l}3,75 \\
4,13\end{array}$ & $\begin{array}{l}1,40 \\
1,39\end{array}$ & $\begin{array}{l}0,11 \\
0,10\end{array}$ & 0,55 & $-2,57$ & $\mathbf{0 , 0 1} 1^{* *}$ \\
\hline Discriminação Étnica (DE) & $\begin{array}{c}\text { Branca } \\
\text { Parda/Negra }\end{array}$ & $\begin{array}{l}3,23 \\
3,81\end{array}$ & $\begin{array}{l}1,82 \\
1,75\end{array}$ & $\begin{array}{l}0,15 \\
0,12\end{array}$ & 0,24 & $-3,05$ & $0,00^{* *}$ \\
\hline Discriminação Sexual (DS) & $\begin{array}{c}\text { Branca } \\
\text { Parda/Negra }\end{array}$ & $\begin{array}{l}3,69 \\
4,01\end{array}$ & $\begin{array}{l}1,73 \\
1,69\end{array}$ & $\begin{array}{l}0,14 \\
0,12\end{array}$ & 0,81 & $-1,73$ & 0,08 \\
\hline Falta de Suporte (FS) & $\begin{array}{c}\text { Branca } \\
\text { Parda/Negra }\end{array}$ & $\begin{array}{l}3,88 \\
4,24\end{array}$ & $\begin{array}{l}1,56 \\
1,51\end{array}$ & $\begin{array}{l}0,12 \\
0,11\end{array}$ & 0,66 & $-2,19$ & $\mathbf{0 , 0 3}{ }^{* *}$ \\
\hline Restrição de Oportunidades (RO) & $\begin{array}{c}\text { Branca } \\
\text { Parda/Negra }\end{array}$ & $\begin{array}{l}4,22 \\
4,48\end{array}$ & $\begin{array}{l}1,42 \\
1,42\end{array}$ & $\begin{array}{l}0,11 \\
0,10\end{array}$ & 0,83 & $-1,77$ & 0,08 \\
\hline
\end{tabular}

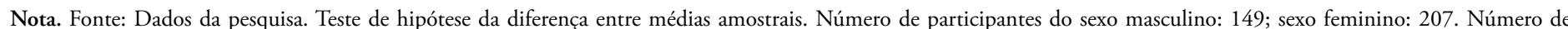
participantes da cor branca: 155; cor parda ou negra: 199. 
Verifica-se que foram significativas as diferenças de percepções de barreiras de carreira entre os sexos de forma geral. Especificamente, verificou-se que existem diferenças significativas nas dimensóes DS e FS. Logo, há falha em rejeitar H1a. Observou-se também, assim como esperado, que foram significativas as diferenças de percepçóes de barreiras quando se considera a cor dos participantes - de forma geral e em DE e FS -, falhando em rejeitar H1b. Destaca-se que, nessa análise, dois grupos foram considerados: cor branca, e cor parda ou negra.

\section{Avaliação do modelo estrutural (H2 a H6)}

Para verificar as hipóteses de relaçóes associativas entre as variáveis, foi estimado o modelo de equaçáo estrutural representado pela teoria de mensuração, conforme a Figura 2.
Os índices de ajustes indicaram que o modelo foi satisfatório, conforme os valores: $[\chi 2=110,468$; g.l. $=33$ $(p<0,001) ; \chi 2 /$ g.l. $=3,348 ; \mathrm{CFI}=0,950 ; \mathrm{TLI}=0,932 ; \mathrm{RMSEA}$ $(90 \% \mathrm{CI})=0,081(0,065-0,098)]$. Os construtos Barreiras de Carreira e Adaptabilidade explicaram 40\% da Empregabilidade. Já a Satisfação apresentou coeficiente de determinação $\left(\mathrm{R}^{2}\right)$ de $21 \%$, sendo explicada por Barreiras de Carreira, Adaptabilidade e Empregabilidade. Para a área de Ciências Sociais, esses efeitos podem ser considerados, respectivamente, como grande e médio (Cohen, 1988). A Tabela 2 demonstra os coeficientes de caminho para avaliaçáo do modelo estrutural, com os indicadores de significância de cada relação de dependência.

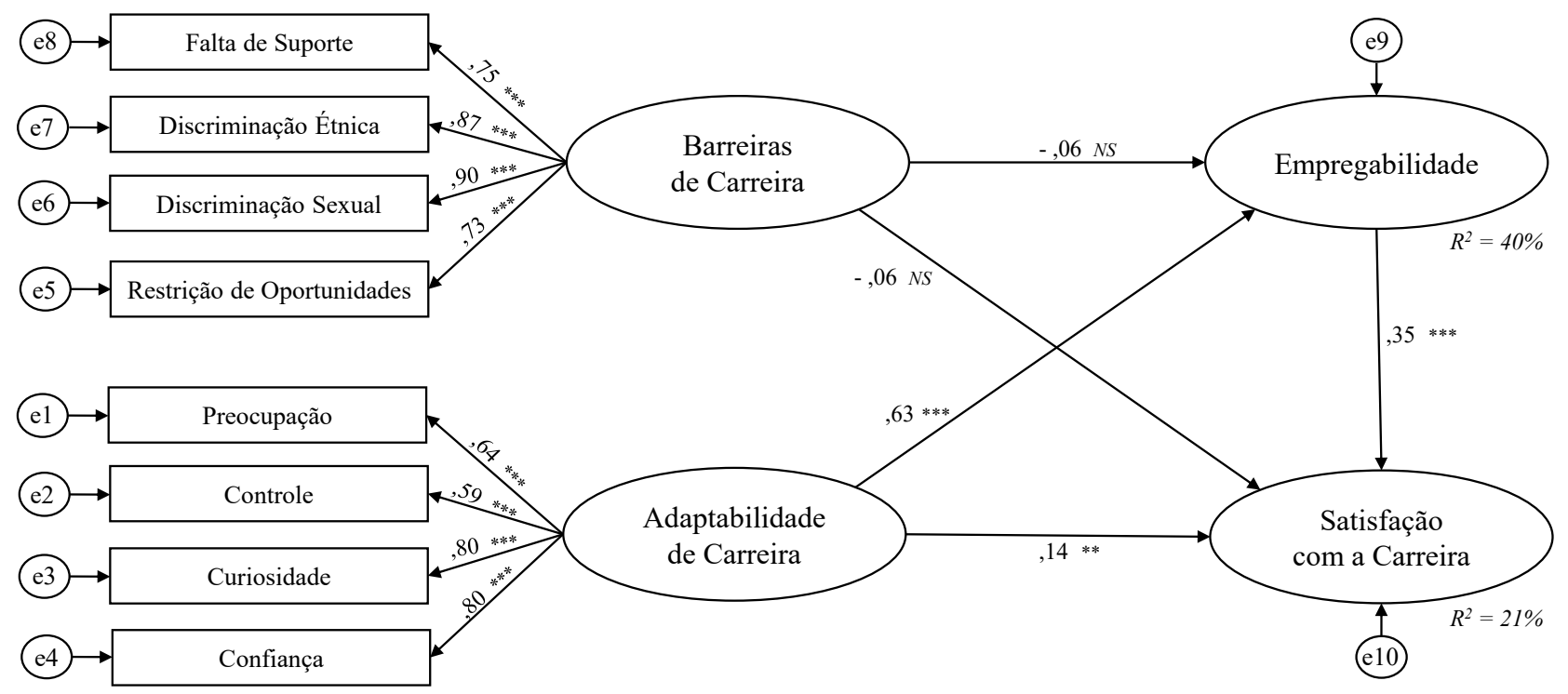

Figura 2. Modelo estrutural.

Fonte: Dados da pesquisa. Resultado do teste do modelo estrutural hipotético proposto pela pesquisa por meio da modelagem de equaçōes estruturais.

Tabela 2. Coeficientes de regressão padronizados.

\begin{tabular}{|c|c|c|c|c|}
\hline Variável Preditora & & Variável Dependente & $\mathrm{B}$ & $p$ \\
\hline Barreiras de Carreira & $\rightarrow$ & Empregabilidade | $\mathbf{H 2}$ & $-0,06$ & 0,21 \\
\hline Barreiras de Carreira & $\rightarrow$ & Satisfação | H3 & $-0,06$ & 0,22 \\
\hline Adaptabilidade & $\rightarrow$ & Empregabilidade | H4 & 0,63 & $0,00^{* * *}$ \\
\hline Adaptabilidade & $\rightarrow$ & Satisfação | H5 & 0,14 & $0,04^{* *}$ \\
\hline Empregabilidade & $\rightarrow$ & Satisfação | H6 & 0,35 & $0,00^{* * *}$ \\
\hline Barreiras de Carreira & $\rightarrow$ & Falta de Suporte & 0,75 & $0,00^{* * *}$ \\
\hline Barreiras de Carreira & $\rightarrow$ & Discriminação Étnica & 0,87 & $0,00^{* * *}$ \\
\hline Barreiras de Carreira & $\rightarrow$ & Discriminação Sexual & 0,90 & $0,00^{* * *}$ \\
\hline Barreiras de Carreira & $\rightarrow$ & Restrição de Oportunidades & 0,73 & $0,00^{* * *}$ \\
\hline Adaptabilidade & $\rightarrow$ & Preocupação & 0,64 & $0,00^{* * *}$ \\
\hline Adaptabilidade & $\rightarrow$ & Controle & 0,59 & $0,00^{* * *}$ \\
\hline Adaptabilidade & $\rightarrow$ & Curiosidade & 0,80 & $0,00^{* * *}$ \\
\hline Adaptabilidade & $\rightarrow$ & Confiança & 0,80 & $0,00^{* * *}$ \\
\hline
\end{tabular}

Nota. Fonte: Dados da pesquisa. Modelagem de equaçóes estruturais para testar as hipóteses (H2 a H6) e a significância das relaçóes de dependência entre as variáveis preditoras e dependentes. 
A partir do exposto, observa-se que os coeficientes de Barreiras de Carreira para Empregabilidade e para Satisfação não foram significativos. Para os demais, as relaçôes estruturais demonstraram-se significativas, variando de 0,14 (Adaptabilidade para Satisfação) a 0,90 (Barreiras de Carreira para Discriminaçáo Sexual). Dessa forma, ao considerar especificamente as hipóteses teorizadas, verificase que $\mathrm{H} 2$ e $\mathrm{H} 3$ são rejeitadas, enquanto há falha em rejeitar as demais, quais sejam: H4, $\mathrm{H} 5$ e $\mathrm{H} 6$.

\section{DISCUSSÃO}

\section{Aspectos exploratórios do modelo teórico}

O perfil sociodemográfico da amostra revela características comuns de estudantes universitários brasileiros: jovens, solteiros e de cor branca. Esse perfil predominante já foi demonstrado em outras pesquisas recentes com concluintes da educação superior (Instituto Nacional de Estudos e Pesquisas Educacionais Anísio Teixeira [Inep], 2017). Ademais, considerando que o maior grupo da amostra estudava no período noturno $(88,0 \%)$, esperava-se que a maioria exercesse atividade remunerada, o que de fato foi verificado $(85,2 \%)$.

Tais dados sugerem possíveis motivos para a preferência dos alunos pelo curso noturno, pois há disponibilidade para o trabalho e, assim, é possível conciliá-lo com os estudos. Essa característica reforça o que Ristoff (2016) verificou em suas análises ao identificar um perfil comum de "estudantetrabalhador" entre os graduandos brasileiros do curso de Administração. Tal característica refere-se a estudantes que trabalham e se sustentam sem precisar de ajuda para financiar os seus gastos e, além disso, trabalham e muitas vezes contribuem com o sustento de suas famílias (ou as sustentam).

Em relação aos construtos investigados, o inventário que mensurou percepçóes de barreiras de carreira apresentou a maior média na dimensão $\mathrm{RO}(4,35)$. Os itens do inventário que mais influenciaram relacionam-se justamente à instabilidade na economia brasileira já instaurada há alguns anos, os quais envolvem a falta de oportunidades de progressão na profissão e a dificuldade de planejar a carreira devido à instabilidade econômica do país. Os resultados vão ao encontro dos indicadores recentes do Instituto Brasileiro de Geografia e Estatística (IBGE, 2020) e do que refletem Barbosa Filho (2017) e Oreiro (2017) a respeito da crise econômica brasileira. Em concordância com os autores, tal crise tem como resultado a presença de maiores dificuldades que precisam ser enfrentadas no mercado de trabalho nacional - como maior número de demissões nas empresas e diminuição da oferta de vagas em empregos formais.
Outros fatores que provavelmente impactaram na dimensão supracitada referem-se às restriçóes de oportunidades de formaçáo educacional e ao conhecimento restrito acerca do mundo do trabalho. Essas percepçóes sugerem que as inconstâncias contemporâneas do mercado de trabalho no Brasil impactam a percepção dos alunos principalmente dos jovens, deixando-os mais inseguros e confusos acerca do desenvolvimento profissional. É possível ter essa inferência uma vez que $78,3 \%$ dos participantes apresentaram idades entre 19 e 30 anos. Esses achados remetem ao que já foi afirmado por Santos e Gimenez (2015), os quais defendem que o segmento juvenil é um dos mais afetados atualmente pelo alto nível de desocupação no país. Além disso, indicadores atuais do IBGE (2020) revelaram que a taxa de desocupação das pessoas mais jovens foi a mais elevada historicamente nos últimos anos.

As dimensões que obtiveram os menores valores de médias para percepçōes de barreiras (DS e DE) referemse especificamente às discriminaçóes pelo sexo e pela cor. Porém, é importante ressaltar que a média em DE foi influenciada pelas características da amostra, já que a maior parte foi de cor branca $(43,3 \%)$. Embora essa dimensão tenha obtido a menor pontuação no IPBC, ela aponta que a discriminação étnica é considerada pelos participantes um empecilho para o desenvolvimento da carreira. LipshitsBraziler e Tatar (2012) e Kim e O’Brien (2018) já destacaram que as percepçóes de barreiras de carreira diferem conforme a cor ou etnia do indivíduo - e tais percepções associam-se diretamente a açóes de discriminação. Isso serve de alerta para ambientes organizacionais e para a sociedade em geral, em que há a urgente necessidade de supressão de qualquer forma de discriminaçáo nos relacionamentos humanos.

Relativamente aos outros instrumentos utilizados, a maior média dentre as dimensóes da EAC foi em CO $(4,25)$, o que sugere que a maioria dos alunos possuía crenças positivas sobre alcance de metas, suas competências e superação de desafios. Esse resultado pode ser associado às crenças de autoeficácia (Bandura, 1978; Lent, Brown, \& Hackett, 1994), em que habilidades como ser eficiente, solucionar problemas ou superar obstáculos demonstramse, na visão dos alunos, como bem desenvolvidas. Assim, nesse caso, a dimensão da confiança reflete a autoeficácia do indivíduo em relaçáo a aspectos diversos de sua própria carreira (ser eficiente e cuidadoso, fazer bem feito, aprender novas tarefas, etc.). Ou seja, reflete que estes demonstram certa confiança na tomada de decisões e na execução de tarefas para o desenvolvimento profissional.

No tocante às demais escalas, a EEP apresentou a média geral de 3,94, demonstrando que os estudantes acreditam que desenvolveram as habilidades necessárias para o trabalho em sua área de formação e que as habilidades já desenvolvidas são facilitadoras no processo de obtenção de 
um emprego. De acordo com Bowling, Eschleman e Wang (2010), essas percepçóes - que se referem ao andamento dos feitos na carreira pelo indivíduo - são medidas importantes, uma vez que evidenciam atitudes positivas em relação ao trabalho. Vianen et al. (2019) também reforçam que a empregabilidade é uma avaliação fundamental em relação aos resultados alcançados na carreira do indivíduo até o momento atual.

Já a ESC obteve média geral mais baixa $(3,16)$, demonstrando que os participantes não estão nem satisfeitos e nem insatisfeitos com a carreira. Verifica-se que um dos fatores de maior influência para o aumento da média baseouse no nível de satisfação com desenvolvimento de habilidades, o que pode ser associado à dimensão de confiança $(\mathrm{CO})$ da EAC - que se destacou como a dimensão de maior média -, e aos achados supracitados sobre a empregabilidade percebida. Nesse sentido, verifica-se que o desenvolvimento de habilidades, sendo uma forma do processo de adaptaçáo na carreira, reflete no nível de satisfação dos alunos, o que está em linha com o entendimento de Ambiel et al. (2016).

\section{Hipótese: percepções de barreiras de carreira}

Com o objetivo de verificar a hipótese inicial deste estudo (H1), foram calculadas as diferenças de percepçóes de barreiras de carreira baseando-se em subamostras dos participantes conforme sexo e cor. Primeiramente, verificou-se que as diferenças de percepçóes de barreiras de carreira foram, de maneira geral, significativas entre os sexos, falhando em rejeitar H1a. As dimensóes DS e FS se diferenciaram significativamente entre homens e mulheres. Salienta-se ainda que as pessoas do sexo feminino obtiveram pontuaçôes mais altas em todas as dimensóes do IPBC.

Os resultados são consistentes com outros estudos que também compararam percepçóes de barreiras entre os sexos (Cardoso, 2009; Faria et al., 2008; Lipshits-Braziler \& Tatar, 2012). Reforçam também as diferenças entre os sexos já apontadas pelos indicadores do IBGE (2020) em relação ao mercado de trabalho brasileiro. Vale destacar, ainda, que o próprio conceito de barreiras de carreira foi originado tendo como base as dificuldades encontradas pelas mulheres para desenvolver suas próprias carreiras (Cardoso, 2009).

Procedeu-se, na sequência, com a avaliação das diferenças de percepções de barreiras entre pessoas de cor branca e de cor parda ou negra. Destaca-se que o último grupo foi criado tendo em vista o desbalanceamento amostral entre a variável demográfica, inviabilizando um número mínimo de 118 participantes de cor negra para a criaçáo de uma terceira subamostra. Constatou-se que as diferenças de percepçóes entre os dois subgrupos foram estatisticamente significativas. Especificamente, as dimensóes DE e FS demonstraram médias significativamente distintas entre pessoas que se declararam de cor branca e de cor parda ou negra. Ressalta-se ainda que o segundo subgrupo (pardos e negros) apresentou médias maiores em todas as dimensóes do inventário.

Considerando isso, há falha em rejeitar $\mathrm{H} 1 \mathrm{~b}$ na populaçáo estudada. Pode-se inferir, nesse sentido, que características sociodemográficas impactam na percepção de barreiras de carreira. Tais resultados estão conforme afirmativa de Lipshits-Braziler e Tatar (2012), que explicam que as percepçóes de dificuldades na carreira variam conforme características individuais, incluindo a cor. Além disso, pesquisas empíricas já verificaram que as barreiras de carreiras são percebidas por pessoas negras com maior intensidade quando comparadas às pessoas de outras cores (Kim \& O’Brien, 2018).

\section{Hipóteses: barreiras, adaptabilidade, empregabilidade e satisfação}

Conforme proposto em $\mathrm{H} 2$ e $\mathrm{H} 3$, as percepçōes de resultados alcançados na carreira são influenciadas por julgamentos de empecilhos na carreira (barreiras). Os indicadores encontrados entre as variáveis sugerem que há influência negativa, o que reforça a teorização de BullockYowell et al. (2011), London (2014) e Silva e Andrade (2016). Porém, não demonstraram que as percepçóes de barreiras de carreira predizem significativamente as crenças de empregabilidade e de satisfação com a carreira. Logo, H2 e $\mathrm{H} 3$ foram rejeitadas.

Tais resultados demonstram também a importância de novas pesquisas que considerem outras dimensóes psicológicas implícitas que possam impactar as associaçóes entre percepções de barreiras de carreira, empregabilidade e satisfação. Um exemplo são as expectativas de autoeficácia, que se inserem na perspectiva sociocognitiva de carreira (Brown \& Lent, 2019; Lent et al., 1994) e que já foram verificadas como influentes no processo de percepção de barreiras de carreira.

Para clarificar, uma situação hipotética. Um indivíduo percebe muitas barreiras que dificultam o desenvolvimento de sua carreira, mas possui crenças elevadas de confiança e autoeficácia - isto é, acredita ser eficiente para realizar tarefas, solucionar problemas, desenvolver habilidades, dentre outras. Com isso, esse indivíduo planeja com frequência e se dedica de forma constante e ativa para sua carreira. Com esse tipo de comportamento, ao atingir anseios profissionais, ele tenderá a impactar suas crenças de empregabilidade e o seu nível de satisfaçáo com a carreira. Logo, o indivíduo poderá perceber muitas barreiras em sua carreira, mas ainda assim apresentar, naquele momento, percepçóes favoráveis de resultados alcançados na carreira. 
Evidências favoráveis a essa situação são explanadas por Cardoso e Moreira (2009), os quais sugerem que pessoas com grande investimento na carreira tendem a planejar mais e, consequentemente, apresentam maior percepção de barreiras de carreira, mas sem que isso corresponda necessariamente a baixas expectativas de autoeficácia ou baixo nível de confiança. Ainda, outra possibilidade para justificar o resultado da não influência de barreiras percebidas no contexto na empregabilidade e na satisfação dos alunos é que tais dificuldades estejam sendo percebidas como características do ambiente econômico, político e social que operam distantemente de suas realidades - isto é, não influenciam diretamente em suas carreiras.

No tocante a $\mathrm{H} 4$ e $\mathrm{H} 5$, os resultados demonstraram que a adaptabilidade prediz significativamente a empregabilidade e a satisfação na carreira, falhando em rejeitar essas hipóteses. A adaptabilidade demonstra ser relevante, uma vez que se trata da habilidade contínua de adaptação dos indivíduos (Johnston, 2016; Savickas, 1997), favorecendo aspectos da vida de forma geral e, mais especificamente, da carreira. Os coeficientes indicaram que, havendo desenvolvimento de habilidades relacionadas à adaptabilidade, é mais provável que o indivíduo perceba positivamente os resultados alcançados na carreira.

Estudos desenvolvidos recentemente concordam com esses achados. A investigação de Silva (2016), por exemplo, evidenciou que a adaptabilidade atua como facilitadora das percepçóes positivas de empregabilidade e de satisfaçáo com a carreira. $\mathrm{O}$ autor explica que o desenvolvimento contínuo de habilidades ajuda o profissional a manter-se empregado, favorecendo retornos positivos no trabalho (como reconhecimento e promoçóes) e, consequentemente, aumentando a satisfaçáo com o desenvolvimento da carreira. Ambiel et al. (2016) também reforçaram a importância da relação entre adaptabilidade e satisfação e afirmam, como exemplo, que a satisfação com o curso pode ser um reflexo do processo de adaptação frente à carreira escolhida.

Sequencialmente, os resultados falharam em rejeitar H6. Nesse sentido, verifica-se que quanto maior o desenvolvimento promovido por experiências desafiadoras de trabalho, bem como o desenvolvimento de competências e aptidóes centrais e de habilidades para conquistar e manter um emprego, maiores são as chances de percepção de sucesso na carreira - o que vai ao encontro do que apontam Lo Presti e Pluviano (2016) e Vianen et al. (2019). É interessante destacar uma última conexáo ao considerar que, dentre os modelos recentes de carreira, um dos mais presentes na literatura - conforme Vasconcellos, Borges-Andrade, Porto e Fonseca (2016) - é a carreira proteana (Hall, 2004). Nesse modelo, uma das premissas teóricas é que a percepção de empregabilidade do indivíduo favorece o sucesso de carreira (Hall, 2004).
Por fim, verificou-se que as percepçóes de barreiras de carreira e de adaptabilidade explicaram $40 \%$ da empregabilidade, sendo considerado um efeito grande em investigaçóes com seres humanos (Cohen, 1988). Já as percepçôes de barreiras de carreira, a adaptabilidade e a empregabilidade explicaram parcialmente a satisfação com a carreira, conforme demonstrado pelo coeficiente de determinação $\left(\mathrm{R}^{2}\right)$ de $21 \%$. É possível explicar esse efeito médio (Cohen, 1988) considerando que outros elementos potenciais podem influenciar a satisfação dos jovens com a carreira. Podem ser encontrados na literatura, como exemplos, as emoçóes relacionadas ao projeto de carreira (Silva \& Andrade, 2016) e a satisfação com a vida (Bowling, Eschleman, \& Wang, 2010).

\section{CONCLUSÕES}

Esta pesquisa tratou de um fenômeno de grande relevância para os indivíduos - a carreira. Considerou, ainda, uma das etapas principais, qual seja, a conclusão da educação superior. $\mathrm{O}$ objetivo foi verificar a influência das percepçóes de barreiras de carreira e de adaptabilidade na empregabilidade e na satisfação com a carreira entre formandos em Administração. De forma inesperada, constatou-se que as percepçóes de barreiras náo foram preditivas da empregabilidade e da satisfaçáo. Já a adaptabilidade demonstrou-se como importante preditora de ambas. O objetivo deste estudo foi, portanto, alcançado.

Em termos de contribuiçóes científicas, destacase inicialmente o estudo de barreiras contextuais de carreira. Verificou-se, por meio da primeira hipótese, que características sociais e demográficas dos indivíduos são indicadores potenciais para a compreensão dessas barreiras. Ainda, as barreiras percebidas no contexto demonstraram não impactar percepçóes de resultados na carreira - que envolveram desenvolvimento de habilidades e competências, valorização profissional, sucesso alcançado, dentre outros. Tais resultados na carreira referiram-se à empregabilidade percebida e ao nível de satisfação. Com isso, esta pesquisa avança, em termos teóricos, na compreensão de barreiras contextuais de carreira referentes à falta de suporte, discriminaçãao e restrição de oportunidades. Conclui-se que tais percepçóes não afetaram diretamente as percepções de resultados alcançados na carreira, e que a percepção de muitas barreiras no ambiente não necessariamente se articulará com menor senso de confiança ou com menor satisfação.

Os resultados reforçaram ainda evidências de que o desenvolvimento contínuo de habilidades para construir as carreiras e, de forma geral, a vida, são importantes influenciadores de percepções favoráveis de capacidades gerais para o trabalho (empregabilidade) e de sucesso na carreira. Tais achados já foram evidenciados em estudos 
prévios e, nesta questáo, esta pesquisa avança principalmente em termos de contribuição prática ao reforçar a importância do desenvolvimento da adaptabilidade de carreira junto a estudantes que estão em momentos de transição na carreira - como é o caso dos finalistas de curso envolvidos neste estudo. As IESs, ao promoverem habilidades de preocupação, controle, curiosidade e confiança junto aos alunos, tendem também a tornar mais favoráveis as percepçóes de empregabilidade, sucesso e satisfação com a carreira.

Em relação às limitações desta investigação, destacase que o modelo teórico averiguado apresentou limitação principalmente no que tange aos construtos preditos pelas percepçóes de barreiras de carreira. Ademais, características da amostra, como a prevalência de cursos noturnos, de IESs privadas e de pessoas de cor branca também devem ser ressaltadas como limitaçóes. Assim, estudos futuros sobre o tema são necessários. Sugerem-se pesquisas que busquem o entendimento mais preciso das percepçóes de barreiras em diferentes grupos sociodemográficos. É relevante também investigar modelos que integrem variáveis potencialmente capazes de influenciar as associaçóes entre barreiras de carreira, empregabilidade e satisfação com a carreira - como a autoeficácia e a satisfação com a vida.

\section{REFERÊNCIAS}

Ambiel, R., Hernández, D., \& Martins, G. (2016). Relaçóes entre adaptabilidade de carreira e vivências acadêmicas no ensino superior. Psicología desde el Caribe, 33(2), 158-168. http://dx.doi.org/10.14482/psdc.33.2.7071

Audibert, A., \& Teixeira, M. A. P. (2015). Escala de adaptabilidade de carreira: Evidências de validade em universitários brasileiros. Revista Brasileira de Orientação Profissional, 16(1), 83-93. Retrieved from http://www.redalyc.org/articulo.oa?id=203041069009

Bandura, A. (1978). Self-efficacy: Toward a unifying theory of behavioral change. Advances in Behaviour Research and Therapy, 1(4), 139-161. https://doi.org/10.1016/0146-6402(78)90002-4

Barbosa Filho, F. H. (2017). A crise econômica de 2014/2017. Estudos Avançados, 31(89), 51-60. http://dx.doi.org/10.1590/s0103-40142017.31890006

Bowling, N. A., Eschleman, K. J., \& Wang, Q. (2010). A metaanalytic examination of the relationship between job satisfaction and subjective well-being. Journal of Occupational and Organizational Psychology, 83(4), 915934. https://doi.org/10.1348/096317909X478557

Brown, S. D., \& Lent, R. W. (2019). A social cognitive view of career development and guidance. In J. A. Athanasou, $\&$ H. N. Perera (Eds.), International handbook of career guidance (Vol. 2, Chap. 7, pp. 147-166). Cham: Springer.

Bullock-Yowell, E., Peterson, G. W., Reardon, R. C., Leierer, S. J., \& Reed, C. A. (2011). Relationships among career and life stress, negative career thoughts, and career decision state: A cognitive information processing perspective. The Career Development Quarterly, 59(4), 302-314. https://doi.org/10.1002/j.2161-0045.2011.tb00071.x

Cardoso, P. (2009). Inventário de percepção de barreiras da carreira (1 ed.). Évora: Departamento de Psicologia da Universidade de Évora. Retrieved from http://hdl.handle.net/10174/2517
Cardoso, P., \& Moreira, J. M. (2009). Self-efficacy beliefs and the relation between career planning and perception of barriers. International Journal for Educational and Vocational Guidance, 9(3), 177. https://doi.org/10.1007/s10775-009-9163-2

Cohen, J. (1988). Statistical power analysis for the behavioral sciences (2 ed). Abingdon, UK: Routledge.

Cozby, P. C. (2003). Métodos de pesquisa em ciências do comportamento (Cap. 7, pp. 141-170). São Paulo: Atlas.

Dahling, J. J., Melloy, R., \& Thompson, M. N. (2013). Financial strain and regional unemployment as barriers to job search self-efficacy: A test of social cognitive career theory. Journal of Counseling Psychology, 60(2), 210-218. https://doi.org/10.1037/a0031492

DeVos, A., DeHauw, S., \&VanderHeijden, B.I. (2011). Competency development and career success: The mediating role of employability. Journal of Vocational Behavior, 79(2), 438447. https://doi.org/10.1016/j.jvb.2011.05.010

Di Fabio, A. (2019). From career development to career management: A positive prevention perspective. In J. A. Athanasou, \& H. N. Perera (Eds.), International handbook of career guidance (Vol. 2, Chap. 10, pp. 209-239). Cham: Springer.

Dunn, T. J., Baguley, T., \& Brunsden, V. (2014). From alpha to omega: A practical solution to the pervasive problem of internal consistency estimation. British Journal of Psychology, 105(3), 399-412. https://doi.org/10.1111/bjop.12046

Faria, L. C., Taveira, M. C., \& Saavedra, L. M. (2008). Exploração e decisão de carreira numa transição escolar: Diferenças individuais. Revista Brasileira de Orientação Profissional, 9(2), 17-30. Retrieved from http://www.redalyc.org/articulo.oa?id=203014920004 
Gamboa, V., Paixão, O., \& Palma, A. I. (2014). Adaptabilidade de carreira e autoeficácia na transição para o trabalho: $\mathrm{O}$ papel da empregabilidade percebida-estudo com estudantes do ensino superior. Revista Portuguesa de Pedagogia, (48-2), 133-156. https://doi.org/10.14195/1647-8614 48-2 7

Greenhaus, J. H., Parasuraman, S., \& Wormley, W. M. (1990). Effects of race on organizational experiences, job performance evaluations, and career outcomes. The Academy of Management Journal, 33(1), 64-86. https://doi.org/10.5465/256352

Hair, J. F., Black, W. C., Babin, B. J., Anderson, R. E., \& Tatham, R. L. (2009). Análise multivariada de dados. Porto Alegre: Bookman.

Hall, D. T. (2004). The protean career: A quarter-century journey. Journal of Vocational Behavior, 65(1), 1-13. https://doi.org/10.1016/j.jvb.2003.10.006

Heijde, C., \& Van Der Heijden, B. (2006). A competence-based and multidimensional operationalization and measurement of employability. Human Resource Management, 45(3), 449476. https://doi.org/10.1002/hrm.20119

Instituto Brasileiro de Geografia e Estatística. (2017). Pesquisa nacional por amostra de domicílios contínua: Algumas características da força de trabalho por cor ou raça. IBGE. Retrieved from ftp://ftp.ibge.gov. br/Trabalho_e_Rendimento/Pesquisa_Nacional_ por Amostra de Domicilios continua/Trimestral/ Caracteristicas da forca de trabalho por cor ou racal Algumas_caracteristicas_da_forca_de_trabalho_por_cor_ ou_raca_2016_04_trimestre.pdf

Instituto Brasileiro de Geografia e Estatística. (2020). Pesquisa nacional por amostra de domicílios contínua: Terceiro trimestre de 2020. IBGE. Retrieved from https:// biblioteca.ibge.gov.br/visualizacao/periodicos/2421/ pnact 2020 3tri.pdf

Instituto Nacional de Estudos e Pesquisas Educacionais Anísio Teixeira. (2017). Indicadores de qualidade da educação superior 2015. INEP. Retrieved from http:// download.inep.gov.br/educacao_superior/indicadores/ legislacao/2017/apresentacao_indicadores_de_qualidade_ da_educacao_superior2015.pdf

Johnston, C. S. (2016). A systematic review of the career adaptability literature and future outlook. Journal of Career Assessment, 26(1), 3-30. https://doi.org/10.1177/1069072716679921

Kim, Y. H., \& O’Brien, K. M. (2018). Assessing women's career barriers across racial/ethnic groups: The perception of barriers scale. Journal of Counseling Psychology, 65(2), 226238. https://doi.org/10.1037/cou0000251

Kuijpers, M., Schyns, B., \& Scheerens, J. (2006). Career competencies for career success. The Career Development Quarterly, 55(2), 168-178. https://doi.org/10.1002/j.2161-0045.2006.tb00011.x

Ladeira, M., Oliveira, M., Melo-Silva, L., \& Taveira, M. (2019). Adaptabilidade de carreira e empregabilidade na transiçâo universidade-trabalho: Mediação das respostas adaptativas. Psico-USF, 24(3), 583-595. http://dx.doi.org/10.1590/1413-82712019240314
Lent, R. W., \& Brown, S. D. (2013). Social cognitive model of career self-management: Toward a unifying view of adaptive career behavior across the life span. Journal of Counseling Psychology, 60(4), 557-568. https://doi.org/10.1037/a0033446

Lent, R. W., Brown, S. D., \& Hackett, G. (1994). Toward a unifying social cognitive theory of career and academic interest, choice, and performance. Journal of Vocational Behavior, 45(1), 79-122. https://doi.org/10.1006/jvbe.1994.1027

Lent, R. W., Brown, S. D., \& Hackett, G. (2000). Contextual supports and barriers to career choice: A social cognitive analysis. Journal of Counseling Psychology, 47(1), 36-49. https://doi.org/10.1037/0022-0167.47.1.36

Lipshits-Braziler, Y., \& Tatar, M. (2012). Perceived career barriers and coping among youth in Israel: Ethnic and gender differences. Journal of Vocational Behavior, 80(2), 545554. https://doi.org/10.1016/j.jvb.2011.08.010

Lo Presti, A., \& Pluviano, S. (2016). Looking for a route in turbulent waters: Employability as a compass for career success. Organizational Psychology Review, 6(2), 192-211. https://doi.org/10.1177/2041386615589398

London, M. (2014). Career barriers: How people experience, overcome, and avoid failure. New York: Psychology Press.

Magalhães, M., \& Bendassolli, P. (2013). Desenvolvimento de carreiras nas organizaçóes. In: L. O. Borges, L. Mourão (Eds.), O trabalho e as organizaçōes: Atuaçōes a partir da psicologia. Porto Alegre: Artmed.

Melo, M. R. (2018). Barreiras de carreira, adaptabilidade $e$ satisfação: Percepçóes de alunos formandos em Administração em Instituiçôes de Educação Superior (Master's thesis). Universidade Federal do Espírito Santo, Vitória, Espírito Santo, Brazil.

Melo, M. R., Martins-Silva, P., \& Andrade, A. (2020). Inventário de percepçãodebarreiras decarreira:Estudocom universitários. Revista Brasileira de Orientação Profissional, 21(1), 67-80. https://dx.doi.org/10.26707/1984-7270/2020v21n107

Oreiro, J. L. (2017). A grande recessão brasileira: Diagnóstico e uma agendadepolíticaeconômica.EstudosAvançados,31(89),7588. https://doi.org/10.1590/s0103-40142017.31890009

Perera, H. N., \& Athanasou, J. A. (2019). Introduction: An international handbook of career guidance. In J. A. Athanasou, H. N. Perera (Eds.), International handbook of career guidance (Vol. 2, Chap. 1, pp. 1-22). Cham: Springer.

Pinho, E., Kilimnik, Z., \& Andrade, D. (2015). A influência da estrutura matricial no comprometimento com a carreira em comparação com a estrutura tradicional: Um estudo de caso na EMATER-MG. REGE - Revista de Gestão, 22(2), 223-239. https://doi.org/10.5700/rege560

Praskova, A., Creed, P. A., \& Hood, M. (2015). Self-regulatory processes mediating between career calling and perceived employability and life satisfaction in emerging adults. Journal of Career Development, 42(2), 86-101. https://doi.org/10.1177/0894845314541517 
Ristoff, D. (2016). Democratização do campus: Impacto dos programas de inclusão sobre o perfil da graduação. Cadernos do GEA (Grupo Estratégico de Análise da Educação Superior no Brasil), 9, 5-62. Retrieved from http://flacso. org.br/?publication=caderno-gea-n9-democratizacao-docampus-impacto-dos-programas-de-inclusao-sobre-operfil-da-graduacao

Santos, A., \& Gimenez, D. (2015). Inserção dos jovens no mercado de trabalho. Estudos Avançados, 29(85), 153-168. http://dx.doi.org/10.1590/S0103-40142015008500011

Savickas, M. L. (1997). Career adaptability: An integrative construct for life-span, life-space theory. The Career Development Quarterly, 45(3), 247-259. https://doi.org/10.1002/j.2161-0045.1997.tb00469.x

Savickas, M. L. (2013). The theory and practice of career construction. In S. D. Brown \& R. W. Lent (Eds.), Career development and counselling: Putting theory and research to work (2. Ed., pp. 147-183). Hoboken: Wiley.

Savickas, M. L. (2016). Reflection and reflexivity during lifedesign interventions: Comments on career construction counseling. Journal of Vocational Behavior, 97, 84-89. https://doi.org/10.1016/j.jvb.2016.09.001

Savickas, M. L., \& Porfeli, E. J. (2012). Career adapt-abilities scale: Construction, reliability, and measurement equivalence across 13 countries. Journal of Vocational Behavior, 80(3), 661-673. https://doi.org/10.1016/j.jvb.2012.01.011

Silva, M. Z. (2016). Pensamentos negativos de carreira e aspectos psicológicos relacionados à satisfação com os resultados alcançados na vida e na carreira. (Master's thesis). Universidade Federal do Espírito Santo, Vitória, Espírito Santo, Brazil.
Silva, M. Z., \& Andrade, A. L. (2016). Avaliando pensamentos negativos sobre a carreira: $\mathrm{O}$ desenvolvimento de uma medida (EPNC). Revista Brasileira de Orientação Profissional, 17(2), 175-187. Retrieved from http://www.redalyc.org/articulo.oa?id=203051246006

Swanson, J., Daniels, K., \& Tokar, D. (1996). Assessing perceptions of career-related barriers: The career barriers inventory. Journal of Career Assessment, 4(2), 219-244. https://doi.org/10.1177/106907279600400207

Trizano-Hermosilla, I., \& Alvarado, J. M. (2016). Best alternatives to cronbach's alpha reliability in realistic conditions: Congeneric and asymmetrical measurements. Frontiers in Psychology, 7(769). https://doi.org/10.3389/fpsyg.2016.00769

Urbanaviciute, I., Pociute, B., Kairys, A., \& Liniauskaite, A. (2016). Perceived career barriers and vocational outcomes among university undergraduates: Exploring mediation and moderation effects. Journal of Vocational Behavior, 92, 12-21. https://doi.org/10.1016/j.jvb.2015.11.001

Vasconcellos, V. C., Borges-Andrade, J. E., Porto, J. B., \& Fonseca, A. M. D. O. (2016). Carreira nas organizaçóes: Revisão da produção brasileira no âmbito do microcomportamento organizacional. Revista Psicologia Organizaçóes e Trabalho, 16(1), 73-87. https://doi.org/10.17652/rpot/2016.1.375

Vianen, A., Pater, I., \& Preenen, P. (2019). Career success: Employability and the quality of work experiences. In J. A. Athanasou, \& H. N. Perera (Eds.), International handbook of career guidance (Vol. 2, Chap. 11, pp. 241-262). Cham: Springer. 


\section{Autoria}

\section{Mariana Ramos de Melo*}

Universidade Federal do Espírito Santo, Programa de PósGraduação em Administração

Av. Fernando Ferrari, no 514, Goiabeiras, 29060-220, Vitória, ES, Brasil.

E-mail: mariramos.melo@gmail.com

(D) https://orcid.org/0000-0001-7826-6050

\section{Priscilla de Oliveira Martins-Silva}

Universidade Federal do Espírito Santo, Programa de PósGraduação em Administração

Av. Fernando Ferrari, no 514, Goiabeiras, 29060-220, Vitória, ES, Brasil.

E-mail: priscillamartinssilva@gmail.com

(D) https://orcid.org/0000-0002-2922-6607

\section{Alexsandro Luiz de Andrade}

Universidade Federal do Espírito Santo, Programa de PósGraduação em Psicologia

Av. Fernando Ferrari, no 514, Goiabeiras, 29060-220, Vitória, ES, Brasil.

E-mail: alexsandro.deandrade@yahoo.com

(D) https://orcid.org/0000-0003-4953-0363

\section{Ralf Luis de Moura}

Universidade Federal do Espírito Santo, Programa de PósGraduaçáo em Administraçáo

Av. Fernando Ferrari, no 514, Goiabeiras, 29060-220, Vitória, ES, Brasil.

E-mail: ralfmoura@gmail.com

(D) https://orcid.org/0000-0002-0170-4056

* Autora Correspondente

\section{Financiamento}

Os autores informam que o presente trabalho foi realizado com apoio da Coordenação de Aperfeiçoamento de Pessoal de Nível Superior - Brasil (CAPES) por meio da bolsa de Mestrado. Os autores agradecem à CAPES pelo apoio financeiro.

\section{Conflito de Interesses}

Os autores informaram que não há conflito de interesses.

\section{Verificação de Plágio}

A RAC mantém a prática de submeter todos os documentos aprovados para publicação à verificação de plágio, mediante o emprego de ferramentas específicas, e.g.: iThenticate.

\section{Contribuições dos Autores}

$1^{\text {a }}$ autora: conceitualização (igual); curadoria de dados (líder); análise formal (líder); aquisição de financiamento (líder); investigação (líder); metodologia (líder); administração do projeto (líder); redação - rascunho original (líder); redação revisão e edição (líder).

2a autora: conceitualização (igual); curadoria de dados (apoio); análise formal (apoio); metodologia (apoio); administração do projeto (apoio); supervisão (líder); redação - revisão e edição (apoio).

3o autor: conceitualização (apoio); curadoria de dados (apoio); análise formal (apoio); metodologia (apoio); supervisão (apoio); redação - revisão e edição (apoio).

40 autor: curadoria de dados (apoio); análise formal (apoio); metodologia (apoio); redação - revisão e edição (apoio).

\section{Direitos Autorais}

A RAC detém os direitos autorais deste conteúdo.

\section{Método de Revisão por Pares}

Este conteúdo foi avaliado utilizando o processo de revisão por pares duplo-cego (double-blind peer-review). A divulgação das informaçốes dos pareceristas constantes na primeira página é feita somente após a conclusão do processo avaliativo, e com o consentimento voluntário dos respectivos pareceristas.

\section{Disponibilidade dos Dados}

Todos os dados e materiais foram disponibilizados publicamente por meio da plataforma Harvard Dataverse e podem ser acessados em:

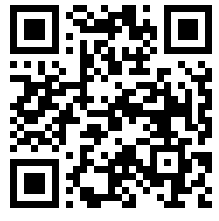

Mariana Ramos de Melo; Priscilla de Oliveira Martins-Silva; Alexsandro Luiz de Andrade; Ralf Luis de Moura, 2021, "Replication Data for: "Barriers, Adaptability, Employability, and Satisfaction: Career Perceptions of Graduates in Administration"", Harvard Dataverse, V1. https://doi.org/10.7910/DVN/UWSMUO

A RAC incentiva o compartilhamento de dados mas, por observância a ditames éticos, não demanda a divulgação de qualquer meio de identificaçáo de sujeitos de pesquisa, preservando a privacidade dos sujeitos de pesquisa. A prática de open data é viabilizar a reproducibilidade de resultados, e assegurar a irrestrita transparência dos resultados da pesquisa publicada, sem que seja demandada a identidade de sujeitos de pesquisa. 